\section{Adesão ao pré-natal de mulheres HIV+ que não fizeram profilaxia da transmissão vertical: um estudo sócio-comportamental e de acesso ao sistema de saúde}

\author{
Adherence to prenatal care by HIV-positive women \\ who failed to receive prophylaxis for mother-to-child \\ transmission: social and behavioral factors and \\ healthcare access issues
}

\author{
1 Serviço de Doenças \\ Infecciosas e Parasitárias, \\ Hospital dos Servidores do \\ Estado, Rio de Janeiro, Brasil. \\ 2 Instituto Fernandes \\ Figueira, Fundação Oswaldo \\ Cruz, Rio de Janeiro, Brasil. \\ Correspondência \\ M. Q. R. Darmont \\ Serviço de Doenças \\ Infecciosas e Parasitárias, \\ Hospital dos Servidores do \\ Estado. \\ Rua Sacadura Cabral 178, \\ 4 o andar, anexo IV, Rio de \\ Janeiro, RJ \\ 20221-903, Brasil. \\ mariana@diphse.com.br
}

\begin{abstract}
This study aimed to elucidate the social and behavioral factors and public health system characteristics that influenced pregnant women's adherence to prenatal care. Forty women diagnosed as HIV-positive by rapid test at delivery were included. Socioeconomic data were collected and a semi-structured interview was conducted. Eight women had $>6$ prenatal visits and 12 had no visits. Interviews were submitted to qualitative content analysis. The themes fit into two blocks: those seen as hindering adherence, like unwanted pregnancy, lack of family support, prior knowledge of serological status, adverse social context, negative experiences with prenatal care, and disbelief towards prenatal care, and those facilitating adherence, like family support, valuing healthcare, wanting a tubal ligation, receptiveness by the healthcare team, and positive previous experience with prenatal care. Improving our understanding of the socio-cultural context should help promote strategies to reach such women and include them in better quality care.
\end{abstract}

Maternal Behavior; Prenatal Care; HIV

\author{
Mariana de Queiroz Rocha Darmont 1 \\ Helena Santos Martins 1 \\ Guilherme Amaral Calvet 1 \\ Suely Ferreira Deslandes 2 \\ Jacqueline Anita de Menezes 1
}

\section{Introdução}

Apesar dos progressos na adesão às condutas recomendadas para a prevenção da transmissão vertical do HIV 1,2, lacunas importantes persistem na capacidade de captação do Sistema Único de Saúde (SUS) ${ }^{3}$ e na adesão das gestantes ao pré-natal ${ }^{4}$. Assim, casos de transmissão vertical que poderiam ser evitados continuam ocorrendo apesar da disponibilidade do diagnóstico e do tratamento da gestante.

Por um lado, observam-se falhas na operacionalização das ações para a prevenção da transmissão vertical do HIV na rede de saúde pública onde, embora a maioria das gestantes tenha sido testada para HIV 5 , muitas ainda chegam ao parto sem ter realizado a sorologia, apontando uma lacuna na implementação dessa prática na atenção básica ao pré-natal, primeira etapa de prevenção da transmissão vertical do HIV.

Uma análise preliminar dos fatores que levaram à perda da oportunidade de prevenção em 187 puérperas, identificadas por teste rápido no parto em 11 maternidades do Grande Rio, Rio de Janeiro, mostrou que $30 \%$ sequer chegaram ao pré-natal, $44 \%$ tiveram de uma a cinco consultas, e apenas $24 \%$ tiveram, pelo menos, seis consultas de pré-natal 6 . Entre os motivos citados, alguns eram relacionados ao sistema de saúde, e outros, às próprias gestantes.

Este trabalho tem por objetivo identificar os fatores sócio-comportamentais e do sistema de 
saúde que, na ótica das gestantes, dificultam ou impedem o acesso ao pré-natal, e, em consequência, às ações profiláticas recomendadas pelo Ministério da Saúde para o controle e diminuição da transmissão vertical do HIV.

Trata-se da primeira parte de um estudo realizado pelo Serviço de Doenças Infecciosas e Parasitárias do Hospital dos Servidores do Estado, com o apoio técnico e financeiro do Ministério da Saúde, Secretaria de Vigilância em Saúde, Programa Nacional de Doenças Sexualmente Transmissíveis e Aids (MS/SVS/PN-DST/AIDS), por meio do Projeto de Cooperação Técnica Internacional $\mathrm{AD} / \mathrm{BRA} / 03 / \mathrm{H} 34$, firmado entre o governo brasileiro e o United Nations Office on Drugs and Crime (UNODC).

\section{Metodologia}

Dados sócio-demográficos quantitativos foram coletados em questionário com perguntas fechadas para contextualizar a população estudada.

Critérios de inclusão e exclusão: foram convidadas a participar da pesquisa mulheres com idade mínima de 18 anos, identificadas como $\mathrm{HIV}+$ por teste rápido no parto, acompanhadas em ambulatório de referência, que pariram há menos de dois anos e chegaram ao parto sem receber a profilaxia da transmissão do HIV para os seus bebês porque não fizeram o pré-natal, não tiveram acesso ao exame ou a seu resultado ou porque não seguiram a orientação recebida. Foram excluídas mulheres com doença mental ou que não aceitaram ser entrevistadas individualmente.

Entre 2 de janeiro e 15 de julho de 2008, foram abordadas 41 mulheres. Uma foi excluída, pois não participou da etapa da entrevista gravada. Foram realizadas 40 entrevistas, com duração média de 30 minutos. Dezenove mulheres foram entrevistadas até dois meses depois do parto, e 21 foram entrevistadas de 3 a 20 meses depois.

A pesquisa foi realizada em duas etapas: na primeira etapa, foi aplicado o termo de consentimento livre e esclarecido, e uma ficha com dados sócio-demográficos (idade, cor ou raça, renda familiar em salários mínimos, estado civil/situação conjugal, escolaridade em anos completos de estudo concluídos, uso de álcool, tabagismo, drogas ilícitas, profissões e/ou ocupações) foi preenchida, e, na segunda, foi realizada uma entrevista individual semi-estruturada, agendada para cerca de duas semanas após.

As entrevistadas foram divididas em três grupos, segundo o número de consultas de prénatal realizadas, de acordo com critérios do Ministério da Saúde 7 e foram classificadas da se- guinte forma: PN0 (mulheres que não realizaram pré-natal); PN1 (mulheres que realizaram de 1 a 5 consultas de pré-natal) e PN2 (mulheres que realizaram 6 ou mais consultas de pré-natal). Na apresentação dos resultados, as mulheres foram identificadas por uma sigla contendo: o número da entrevistada (M1 a M41), a idade (I18 a I43), o grupo (PN0, PN1 ou PN2) e a paridade (P1 a P8). Assim, por exemplo: M14_I27_PN1_P3 designa a décima quarta entrevistada, 27 anos, que realizou de 1 a 5 consultas de pré-natal e teve três partos.

Os dados foram construídos a partir da entrevista individual semi-estruturada. Houve a elaboração de um roteiro no qual foi abordada a compreensão das puérperas sobre os seguintes temas: gestação, pré-natal, assistência, aconselhamento pré e pós-teste anti-HIV, saúde. O roteiro foi criado no sentido de orientar uma "conversa”, visando apreender o ponto de vista dos sujeitos entrevistados, ou seja, foram permitidos o livre discurso e, ao mesmo tempo, o delineamento da conversa, no sentido de manter a entrevista sintonizada com os objetivos da pesquisa ${ }^{8}$. As entrevistas foram realizadas em uma sala de acesso restrito onde as mulheres puderam dar seus depoimentos sem serem interrompidas e sem a presença de outras pessoas.

As entrevistas foram gravadas, transcritas e classificadas de acordo com eixos temáticos definidos nos instrumentos. $\mathrm{O}$ acervo foi organizado em torno de dois blocos temáticos: (a) gestação (gestações anteriores; gestação atual - aceitação); tentativas de aborto; reação do pai e da família em relação à gestação; situação de vida); (b) pré-natal (representações acerca do pré-natal; experiências atuais e anteriores de pré-natal; avaliação e sugestões sobre o pré-natal).

O material discursivo foi codificado e trabalhado consoante à valorização dos núcleos de sentido, seguindo as técnicas de abordagem descritas por Bardin ${ }^{9} \mathrm{e}$ adaptadas por Minayo ${ }^{10}$. O acervo foi analisado a partir das seguintes etapas: "leitura flutuante"; definição de unidades de registro e recorte; definição de núcleos de sentido; identificação das categorias empíricas; elaboração de hipóteses inferenciais a partir das evidências e pistas oriundas do acervo. O processo interpretativo foi concluído após o confronto com a literatura que aborda as categorias teóricas de: adesão ao pré-natal; acesso; acolhimento.

O referencial teórico que guiou o processo interpretativo ancorou-se na categoria analítica “adesão”. Tomamos Santos 11 (p. 34) como autor central a partir de sua definição conceitual: "Adesão a tratamentos médicos (ou 'compliance', em inglês) é uma perspectiva de abordagem que leva em conta as ações e omissões para certos compor- 
tamentos, de interesse médico, de um determinado indivíduonacondiçãodepacienteclínico. Caracterizada como um processo, a questão não é tão simples como aparenta, pois não se esgota nos gestos e nas atitudes imediatamente observáveis, sendo, pelo contrário, parte de um todo comportamental mais complexo que chega a incluir outros atores sociais. Além disso, apresenta variações significativas de uma cultura para outra e, mesmo dentro de uma mesma cultura, de um segmento cultural para outro". Ainda segundo Santos 11, três componentes desse processo são: a noção de doença que possui o paciente, o lugar do médico em seu imaginário e a idéia de cura ou a melhoria que se forma na mente daquele que está em tratamento.

O Termo de Consentimento Livre e Esclarecido foi obtido de todas as participantes, e o protocolo dessa pesquisa foi aprovado pelo Comitê de Ética do Hospital dos Servidores do Estado, com o número 000.284, em 9 de julho de 2007.

\section{Resultados}

\section{Caracterização das mulheres}

Das 40 entrevistadas, 12 não tiveram nenhuma consulta de pré-natal (PNO), 20 tiveram de 1 a 5 consultas (PN1), e oito tiveram 6 consultas ou mais (PN2).

A maioria das mulheres era natural do Rio de Janeiro, tinha entre 20 e 30 anos no momento da entrevista e se declarou não branca. Quase todas tinham renda pessoal igual ou inferior a um salário mínimo. Menos da metade tinha renda familiar mensal superior a um salário mínimo. Apesar disso, pouco menos da metade residia em domicílio próprio.

Duas pacientes eram analfabetas, mas a média da escolaridade foi de sete anos. Mais de dois terços das entrevistadas não estavam trabalhando ou exercendo uma atividade no momento da inclusão no estudo. Atividades ligadas à informalidade sem nenhum vínculo empregatício ou garantias trabalhistas foram citadas: panfletagem, camelô, catadora de latinhas, lavadeira, dona de Kombi (lotação) e vendedora de batatas. Somente cinco mulheres disseram exercer atividades que, agrupadas, poderiam ser chamadas de "trabalho doméstico”, como empregada doméstica, passadeira e faxineira. Uma mulher informou exercer a função de técnica de enfermagem. Somente $10 \%$ (4/40) fizeram uso de drogas ilícitas durante a gravidez.

Entre as 40 entrevistadas, 24 moravam com seus parceiros/cônjuges por um período mediano de 30 meses com diferença entre os grupos: PN0 (40 meses), PN1 (36 meses) e PN2 (24 meses).
Em relação ao número de gestações e partos, a mediana de gestações em todos os grupos foi de 4,0 gestações. No grupo de mulheres que não realizou pré-natal, predominaram as pacientes multíparas ( $\geq 2$ partos) (11/12).

\section{A adesão ao pré-natal}

Os principais temas que emergiram das entrevistas foram agrupados da seguinte forma: os motivos que dificultaram a adesão ao pré-natal e os que favoreceram a adesão segundo a perspectiva êmica das entrevistadas. A seguir, tais temas são apresentados segundo seus principais núcleos de sentido.

\section{- Motivos para não-adesão ao pré-natal}

\section{(a) Aceitação da gestação}

As narrativas mostram que a gravidez surpreendeu a maioria das mulheres (34 em 40) que não planejavam engravidar naquela oportunidade. Nesse grupo, podemos distinguir: as mulheres que não planejaram, mas que ficaram felizes com a gestação, as que não planejaram e tiveram dificuldade para aceitar a gestação e as que não planejaram e pensaram em abortar ou até mesmo fizeram alguma tentativa concreta nesse sentido.

As mulheres que não planejaram a gestação, mas que desejavam, em algum momento, engravidar ficaram felizes ao saber que estavam grávidas. A maioria pertencia ao grupo de mulheres que fez o pré-natal.

Pode-se perceber que algumas, apesar de desconfiarem da gravidez, demoraram a fazer o exame confirmatório. Em outras ocasiões, a dificuldade de aceitar o fato de estar grávida fez com que a mulher passasse por um momento de negação, no qual, apesar de experiências prévias e conhecimento das mudanças corporais da gravidez, deixou de reconhecer o seu estado até um período avançado. Como no trabalho de Cechim et al. ${ }^{4}$ que atribuem o fato à falta de planejamento familiar, a descoberta tardia da gestação constituiu fator importante para retardar a entrada da mulher no pré-natal.

“... aí eles fizeram exame pra ver, que eu tava com a barriga muito grande, nem eu sabia que eu tava grávida... Nessa fase eu tava com quase perto de ganhar já!" (M16_I43_PN0_P5).

As mulheres que não planejaram a gestação e que relutaram em aceitá-la citaram o número de filhos e problemas financeiros como os principais fatores na dificuldade de aceitação da gravidez. Esse período foi, muitas vezes, marcado por uma reação depressiva, que elas descreveram 
como: sono, falta de ânimo, vontade de ficar deitada e tristeza. Alterações fisiológicas próprias do período, como náuseas, sonolência e tonteiras, podem reforçar o quadro descrito por essas mulheres como "preguiça", constituindo também um importante obstáculo para a procura do prénatal, na medida em que precisam acordar muito cedo para tentar conseguir um atendimento nos ambulatórios de pré-natal.

"Preguiça! ...não tava aguentando levantar da cama, só queria ficar dormindo...” (M04_I28_ PN0_P5).

A ideia de abortar ao receber a notícia da gravidez foi mencionada por várias mulheres, seja por já ter muitos filhos ou por se sentir sem condições de criar mais um. As falas evidenciam o temor da gestante de se ver sozinha com o(s) filho(s), sem o suporte do companheiro. Uma das entrevistadas, 33 anos e usuária de drogas, descobriu ser soropositiva aos 14 anos e abortou várias vezes porque, na época do diagnóstico (1989), recebeu a informação, comum naquela época, de que, por ser HIV+, não deveria ter filhos sob pena de passar o vírus para o bebê. A intenção de abortar e as tentativas de aborto foram citadas como outro motivo para a demora em buscar a assistência do pré-natal.

\section{(b) Falta de apoio do parceiro}

Quando indagadas sobre a reação do parceiro à gestação, 18 das 40 entrevistadas disseram que não tiveram o apoio do parceiro ao contar que estavam grávidas ou que esse, após inicialmente manifestar apoio, mudou de atitude no decorrer da gravidez. A falta de apoio podia ser percebida pela mulher a partir da atitude e do comportamento do parceiro. A ausência do pai do bebê parecia gerar na mulher sentimentos de depressão e desamparo vivenciados como um prenúncio de abandono.

"Ele me deixava muito sozinha, eu ficava muito triste, eu não queria saber de nada! Eu ficava só chorando!" (M04_I28_PN0_P5).

As motivações listadas pelas mulheres para a não aceitação paterna da gravidez e consequente falha de suporte desse companheiro foram variadas: o homem já tinha outros filhos de relacionamentos anteriores, o casal já possuía muitos filhos e dificuldades econômicas ou mesmo situações de severa pobreza. Pelo menos em um caso, a mulher achou que o companheiro não queria um filho por ela ser soropositiva para HIV.

"Ele não falou nada, ficou quieto. Ficou olhando pra minha cara. Pela cara dele. Ele não queria não. É. Ele não quer por causa da doença" (M41_I37_PN0_P8; desde o parto anterior, a mulher sabia ser soropositiva).

\section{(c) Conhecimento prévio da soropositividade}

Cinco mulheres já sabiam ser soropositivas para HIV antes mesmo de engravidar. Algumas tentaram esconder o fato da equipe de saúde seja por medo de serem discriminadas pelos profissionais ou do seu status se tornar público na vizinhança do seu local de moradia e até mesmo na sua própria família. No caso de uma delas, esse foi o motivo que alegou para não procurar o pré-natal.

As questões relativas aos problemas de acesso e falta de suporte para ida aos serviços configuraram sentidos significativos para todas as entrevistadas. A situação de vida das entrevistadas mostrou contribuir de forma significativa na dificuldade de acesso aos serviços de saúde e, particularmente, ao pré-natal. Questões relativas à violência, à falta de suporte social e financeiro foram mencionadas. A realidade social aparece no retrato da violência urbana vivenciada pelas mulheres que apontaram os frequentes episódios de tiroteios e assaltos em suas comunidades como obstáculos no caminho do pré-natal. Outros problemas de acesso disseram respeito à distância dos serviços de saúde, aos gastos de passagens, ao medo de perder o emprego e à falta de suporte para deixar os filhos. Num trabalho semelhante com gestantes no Rio Grande do Sul, a falta de dinheiro para o transporte e o não ter com quem deixar os filhos também foram citados como fatores de não-adesão ${ }^{4}$.

"Porque eu não tinha o dinheiro de passagem mesmo (...) Às vezes, até eu tinha, mas olhava pro lado, 'tem que comprar o leite dos meninos"' (M02_I24_PN1_P3).

\section{(d) Experiências negativas de atendimento}

O agravamento da falta de recursos humanos nas unidades básicas de saúde contribuiu para dificultar mais ainda o acesso da população aos postos que realizam pré-natal. A narrativa das entrevistadas mostra que muitas avaliaram que houve uma piora dos serviços de pré-natal quando comparado a experiências de gestações anteriores. $\mathrm{O}$ aumento na burocracia para dar início ao pré-natal, a alta rotatividade dos profissionais, a escassez de recursos laboratoriais nas unidades de saúde, a ausência de entrosamento entre as unidades, o fechamento de postos de atendimento e a mobilização dos serviços de saúde para enfrentar epidemias como a de dengue foram apontados nas entrevistas.

"Porque eu moro numa área de risco. Morava né? Quando era pra mim ir estava dando tiros. (...) Até eu me mudar (...) procurei o posto mais próximo. (...) fui em novembro. Primeiro eles falaram 
que lá não estava fazendo o exame, o teste da gravidez. Eu fui com a ultra-sonografia, aí falaram que não tinha médico, (...) Marcou só pra maio, em maio eu já tinha ganhado. Aí não voltei mais. Desisti" (M33_I28_PN0_P6; fez pré-natal nas cinco gestações anteriores).

“(...) acordar 5 horas da manhã pra pegar maior fila, pra pegar número, (...) Fiquei na fila, peguei o número, só que a médica não foi, aí eu desisti de fazer" (M26_I20_PN0_P1).

A luta contra a burocracia dos serviços de saúde é descrita por algumas mulheres como verdadeiras sagas na sua busca de atendimento contra as barreiras construídas pelo sistema.

“(...) Fiquei mais de uma hora na fila esperando. _ Identidade, está com você? _Seu CPF? _Está comigo _ Cartãozinho do SUS... Falei assim:_Que cartão? Eu não tenho cartão do SUS não. Aí ele: Seu prontuário aqui, qual é? Eu falei assim:_Eu também não sei qual é, eu não tenho prontuário aqui (...) Ele falou assim: _. Agora só é atendida com o cartãozinho do SUS e tem que ter o número do prontuário" (M38_I25_PN1_P4).

Em outro exemplo emblemático, o médico condicionou a marcação no programa de prénatal ao exame confirmatório da gestação, mesmo a mulher estando em período avançado de gravidez.

Algumas entrevistadas se ressentiram de não serem atendidas em nenhum momento por médicos, e sim por enfermeiros, auxiliares de enfermagem ou agentes comunitários. Expressam sentimentos de desconfiança e insegurança quanto à qualidade da assistência prestada ao pré-natal.

“Falaram, só que a gente não conversa com o médico né, é o moço na porta que... Aquele pessoal, auxiliar de enfermagem" (M02_I24_PN1_P3).

Nos grupos de mulheres com baixa ou nenhuma adesão ao pré-natal (PN0 e PN1), surgiu, nos relatos, de forma muito intensa, a falta de acolhimento nas unidades de saúde. As entrevistadas se queixaram do mau humor dos profissionais, da falta de diálogo com o médico e da falta de atenção por esse profissional, que, não raro, é mostrado como apressado e agressivo.

“... Ele gritava com as pessoas, (...) ele não perguntava nada, entendeu, era muito ignorante, (...)" (M24_I24_PN1_P5).

"... Inclusive tem uma doutora que nem pra você olha, não sabe nem com quem está falando" (M29_I27_PN1_P8).

Relatos mostram que algumas mulheres se sentem discriminadas por terem muitos filhos e estarem grávidas, por estarem infectadas pelo vírus do HIV e engravidarem, por serem usuárias de drogas ou mesmo por não terem feito o prénatal.
“Não. Não fui. No pré-natal não fui mais (...) Achava que os outros ficavam me olhando diferente" (M13_I22_PN0_P4; já sabia ser soropositiva de gestação anterior).

A dificuldade de comunicação e a pouca clareza na linguagem do profissional foram também citadas. Entender o contexto socioeconômico no qual as mulheres estão inseridas é fundamental para que as indicações e prescrições do médico possam ser seguidas. A falta de compreensão por parte dos profissionais de saúde da realidade social e das dificuldades que as mulheres vivenciam contribui para essas não aderirem ao pré-natal. A formação do médico não o prepara para atender uma população pobre que depende do SUS 12 .

O grupo que não frequentou pré-natal atribuiu ainda outros motivos para tal comportamento. Experiências consideradas invasivas, típicas da rotina clínica, foram mencionadas por uma das entrevistadas como aspectos importantes para desistir do pré-natal. Ter de "abrir as pernas", tirar a roupa e sofrer com um profissional que lhe "enfia o dedo" dão a dimensão do desconforto e invasão percebida a partir do toque ginecológico.

“O pré-natalébotar a mulher deitada naquela mesa, passar o gel, perguntar aonde que tá doendo, ver o bebê e pronto, sem ter que ficar enfiando o dedo" (M22_I24_PN0_P2).

Contudo, um dos núcleos de sentidos chama a atenção por revelar práticas e concepções arraigadas entre gerações de não-adesão ao pré-natal, delineando "tradições familiares" de descrédito. Entrevistadas relatam que já tiveram outras gravidezes e, assim como suas mães e irmãs, nunca recorreram ao pré-natal. Essa experiência parece se consolidar com aparentes desfechos positivos quanto à saúde do bebê, dando-lhes a ideia de que o pré-natal seria dispensável às "gestações normais".

“... eu fui mais pelo lado da minha mãe também, porque minha mãe tem sete filhos, ela nunca fez pré-natal" (M28_I19_PN0_P2).

Outras concepções associam o pré-natal a ter que fazer exames, seguir dieta e receber prescrição de vitaminas. Também atribuem importância à determinação da data do parto e do sexo do bebê, desvalorizando o profissional que "erra" na previsão.

“O pré-natal é só para poder ver como é que a criança está e chega na hora tem médico (...). Que diz que a criança vai nascer num dia e nasce no outro, que diz o sexo errado e tudo mais" (M28_I19_PN0_P2).

O mito de que o serviço público não presta expressa a frustração de não ter o dinheiro para pagar consulta ou exames particulares ou de não ter um plano de saúde, visto como a solução dos 
problemas de atendimento. O mito é reforçado por imagens negativas veiculadas em alguns noticiários televisivos.

"Vejo muita coisa, vejo enfermeira causar a morte de neném, de gente. (...) Dá injeção... dá remédio errado, a criança morrer. Eu vejo na televisão" (M41_I37_PN0_P8).

Interessante notar que a força da mídia televisiva é mencionada por outra entrevistada ao explicar que as informações disponíveis nas unidades de saúde não chegam nas comunidades.

"Porque informação não chega lá. Só televisão” (M33_I28_PN0_P6).

\section{- Motivos para adesão ao pré-natal}

Entre os fatores citados como motivação para o pré-natal, foram citados o apoio do parceiro e da família, o discurso do cuidado com a própria saúde, a demanda de laqueadura tubária, o acolhimento por parte dos profissionais de saúde, a valorização do atendimento pelo mesmo profissional em consultas e até em gestações sucessivas e as experiências positivas de organização do atendimento.

\section{(a) Apoio do parceiro e da família}

O grupo de mulheres que aderiram ao pré-natal relata o quanto foi valioso o apoio que receberam do parceiro, dos pais, dos parentes mais próximos, salientando a importância de ter alguém com quem pudessem conversar abertamente. Também o fato de a gravidez ser desejada contribuiu para a adesão. Entre as mulheres que fizeram um pré-natal completo, a maioria tinha o apoio do parceiro e/ou da família.

"Eu tive uma gravidez ótima. Muito boa. Tive muita atenção de todo mundo, marido, todo mundo" (M30_I19_PN2_P3).

"Nessas duas meninas, eu estava morando lá com a minha mãe, não é? (...) Está na hora! Acorda! Levanta! (...) Vamos embora! Vou até ali contigo" (M08_I31_PN0_P4; não fez pré-natal na última gestação, pois a mãe não estava mais por perto).

\section{(b) Discurso de valorização do cuidado com a saúde}

No grupo das mulheres que fez um pré-natal dentro do padrão considerado adequado pelo Ministério da Saúde, encontramos, com mais frequência, o discurso de valorização do cuidado com a saúde e a noção da importância da prevenção de doenças a partir dos exames.

"Eu tenho o cartão até hoje lá do pré-natal. Eu sempre fui muito coisa com o pré-natal. Sempre muito cuidadosa" (M03_I29_PN2_P3).

\section{(c) Laqueadura tubária como motivação para o pré-natal}

Como parte de uma política de incentivo ao prénatal e devido às restrições legais 13 para a laqueadura tubária, esse procedimento deveria ser precedido de um número suficiente de consultas de pré-natal para a avaliação médica da indicação e para a obtenção das autorizações exigidas. Assim, o desejo de esterilização definitiva constituiu a motivação de duas entrevistadas para frequentar o pré-natal.

\section{(d) Acolhimento por parte dos profissionais de saúde}

Entre as mulheres que frequentaram todas as consultas de pré-natal, algumas referem ter se sentido muito apoiadas por membros da equipe de saúde, que mantinham vínculo com elas e se interessavam pelo seu bem-estar, destacando, especialmente, o fato de terem sido tratadas sem preconceito, uma preocupação permanente das mesmas. Ter uma "escuta" cúmplice e com privacidade foi muito valorizado por elas. Durães-Pereira et al. 14 (p. 474), num estudo com gestantes na periferia de São Paulo, ressaltaram a importância "da escuta e do diálogo como estratégia de qualidade na assistência à gestante".

"E dependendo das médicas assim, era muito companheira, conversa" (M15_I24_PN2_P4).

$\mathrm{O}$ acervo mostrou que metade das entrevistadas, quando abordadas sobre a história de pré-natais anteriores, relataram experiências positivas que favoreceram a realização do pré-natal futuro. Um dos fatores apontados para a boa adesão foi a relação com a equipe de saúde, principalmente quando eram atendidas pelos mesmos profissionais ao longo do pré-natal, assim como nas gestações anteriores. A fala dessas mulheres sugere que a manutenção da equipe no serviço de saúde confere confiabilidade e segurança à população atendida.

"Ele [o médico] do mesmo jeito. Ele até me encarnava: Ué! Você aqui de novo! (...) Até as faxineiras lá já me conhecia [risos]” (M25_I24_PN2_P5).

\section{(e) Experiências positivas de organização da assistência}

Foram descritos exemplos de organização do atendimento em dois centros de saúde no $\mathrm{Mu}$ nicípio do Rio de Janeiro: no primeiro, a gestante tem atendimento prioritário e, no outro, todas as gestantes são convidadas a uma palestra semanal às segundas-feiras, saindo com a consulta já marcada. Não se exige que as mulheres cheguem de madrugada na fila. Uma mãe de muitos filhos 
lembrou que, no passado, ao chegar ao posto para atendimento pré-natal, era coletada amostra de urina para teste in loco, disponibilizando o resultado do teste de gravidez na hora e marcando a consulta em seguida.

\section{Discussão e considerações finais}

O comportamento das entrevistadas, enquanto gestantes em busca de assistência pré-natal, remete a estudos sobre itinerários terapêuticos em situações de pobreza como os descritos por Gerhardt 15 (p. 2461), que mostra que "além dos limites das condições materiais de vida, os indivíduos constroem as estratégias de acordo com suas capacidades, suas histórias de vida e suas experiências individuais". Cabe lembrar que a maioria dessas mulheres vive em situação de penúria, com famílias numerosas, enfrentando escolhas difíceis como comprar comida para seus filhos ou cuidar de sua saúde.

As barreiras de acesso ao pré-natal enfrentadas pelas gestantes do nosso estudo têm muito em comum com aquelas descritas por Araújo et al. ${ }^{16}$ em unidades básicas de saúde e unidades de saúde da família em Fortaleza, Ceará, que apontam, como principais problemas, as situações que comprometem a marcação da consulta, o déficit na captação precoce da gestante na comunidade e a não priorização do atendimento à gestante.

O sistema de saúde parece não estar preparado para atender às necessidades dessa população, como levantado numa pesquisa recente realizada em áreas de favelas no Rio de Janeiro que aponta "a necessidade de os profissionais de saúde serem capacitados para lidar com as adver- sidades da vida e ampliar a escuta do sofrimento e adoecimento" e questiona "se a racionalidade do modelo biomédico, pautada na lógica das doenças, permite espaço para o acolhimento e a escuta" 17 (p. 35).

O Ministério da Saúde 18 define acolhimento como "uma ação tecno-assistencial que pressupõe a mudança da relação profissional/usuário e sua rede social através de parâmetros técnicos, éticos, humanitários e de solidariedade, reconhecendo o usuário como sujeito e participante ativo no processo de produção da saúde" (p. 5). Aponta a necessidade de restabelecer, no cotidiano, o princípio da universalidade do acesso e cita as dificuldades geradas pela organização burocrática dos serviços "a partir das filas por ordem de chegada sem avaliação do potencial de risco, agravo ou grau de sofrimento" (p. 7).

Exemplos de racionalização do atendimento citados nas entrevistas, como a prioridade ao atendimento de gestantes e a realização de palestras semanais que, além de atingir um grupo maior, facilitam a expressão das dúvidas e a troca de informações em linguagem accessível, mostram que é possível aumentar a qualidade do cuidado sem sobrecarregar as equipes de saúde. Durães-Pereira et al. ${ }^{14}$ mostraram como, mesmo em situação de escassez de recursos humanos, é possível oferecer atendimento pré-natal de qualidade, na ótica das usuárias, por meio da escuta e do diálogo.

A compreensão do contexto sociocultural em que estão inseridas essas mulheres deveria permitir a construção de estratégias capazes de alcançá-las e resgatá-las para um sistema de saúde mais acolhedor tal como concebido nos ideais da Política Nacional de Humanização 19. 


\section{Resumo}

Objetivamos compreender os fatores sócio-comportamentais e do Sistema Único de Saúde (SUS) que, na visão de mulheres identificadas como HIV+ por teste rápido no parto, dificultaram ou impediram a adesão ao pré-natal. Foram incluídas 40 mulheres, das quais apenas oito tinham tido seis consultas ou mais. Foi utilizada a abordagem qualitativa, com entrevistas semi-estruturadas. Os dados foram analisados seguindo os preceitos da análise temática. Os resultados foram agrupados em dois blocos: os que dificultaram a adesão ao pré-natal: não aceitação da gestação, falta de apoio familiar, conhecimento prévio da soropositividade, contexto social adverso, experiências negativas de atendimento e práticas e concepções de descrédito em relação ao pré-natal, e os que favoreceram a adesão: apoio familiar, discurso de valorização do cuidado com a saúde, desejo de laqueadura tubária, acolhimento pela equipe de saúde e experiências positivas de assistência. Uma compreensão melhor do contexto sociocultural deveria permitir a construção de estratégias capazes de resgatar essas mulheres para um sistema de saúde mais acolhedor

Comportamento Materno; Cuidado Pré-Natal; HIV

\section{Colaboradores}

M. Q. R. Darmont e H. S. Martins realizaram a coleta, análise, interpretação dos dados e redação do artigo. G. A. Calvet participou da elaboração do banco de dados, análise, interpretação dos dados e redação do artigo. S. F. Deslandes participou da redação e revisão do texto para publicação, além de fornecer consultoria sobre análise, formatação e interpretação dos dados qualitativos. J. A. Menezes participou da análise, interpretação dos dados e redação do artigo.

\section{Agradecimentos}

À Dra. Cristina Possas e sua equipe da Unidade de Pesquisa e Desenvolvimento Tecnológico do Departamen to de Vigilância, Prevenção e Controle das DST e Aids do Ministério da Saúde - Daniel Torres Deolindo, Andrea Paula Zarat, Edilson Simplício, entre outros - pela atenção e gentileza no decorrer da pesquisa. Ao Projeto de Cooperação Técnica Internacional AD/BRA/03/H34 entre o governo brasileiro e United Nations Office on Drugs and Crime (UNODC) pelo financiamento.

\section{Referências}

1. Cavalcante MS, Silveira ACB, Ribeiro AMS, Ramos Júnior AN. Prevenção da transmissão vertical do vírus da imunodeficiência humana: análise da adesão às medidas de profilaxia em uma maternidade de referência em Fortaleza, Ceará, Brasil. Rev Bras Saúde Mater Infant 2008; 8:473-9.

2. Ramos Jr. AN, Matida LHI, Saraceni V, Veras MASM, Pontes RJS. Control of mother-to-child transmission of infectious diseases in Brazil: progress in HIV/AIDS and failure in congenital syphilis. Cad Saúde Pública 2007; 23 Suppl 3:S370-8.
3. Fernandes RCSC, Araújo LC, Medina-Acosta E. O desafio da prevenção da transmissão vertical do HIV no Município de Campos dos Goytacazes, Rio de Janeiro, Brasil. Cad Saúde Pública 2005; 21:1153-9.

4. Cechim PL, Perdomini FRI, Quaresma LM. Gestantes HIV positivas e sua não-adesão à profilaxia no pré-natal. Rev Bras Enferm 2007; 60:519-23.

5. Souza Júnior PR, Szwarcwald CL, Barbosa Júnior A, Carvalho MF, Castilho EA. HIV infection during pregnancy: The Sentinel Surveillance Project, Brazil, 2002. Rev Saúde Pública 2004; 38:764-72. 
6. Martins HS, Darmont MQR, Calvet GA, Menezes JA. Perfil de uma coorte de puérperas HIV-positivo identificadas por teste rápido no parto e que não receberam profilaxia para a transmissão vertical do HIV durante o pré-natal acompanhadas no Hospital dos Servidores do Estado do RJ. In: VII Congresso Brasileiro de Prevenção das DST/Aids. http:// sistemas.aids.gov.br/congressoprevencao/2008/ dmdocuments/trabalhos_aprovados.pdf (acessado em 02/Nov/2009).

7. Área Técnica de Saúde da Mulher, Departamento de Ações Programáticas Estratégicas, Secretaria de Atenção à Saúde, Ministério da Saúde. Pré-natal e puerpério: atenção qualificada e humanizada - manual técnico. Brasília: Ministério da Saúde; 2006. (Série Direitos Sexuais e Direitos Reprodutivos - Caderno, 5).

8. Bauer MW, Gaskell G. Pesquisa qualitativa com texto, imagem e som: um manual prático. Petrópolis: Editora Vozes; 2004.

9. Bardin L. Análise de conteúdo. Lisboa: Edições 70; 1979.

10. Minayo MCS. O desafio do conhecimento: pesquisa qualitativa em saúde. São Paulo: Editora Hucitec; 2006.

11. Santos JFFQ. Adesão a tratamentos médicos. Psiquiatr Prat Med (São Paulo) 2001; 33:34-6.

12. Cotta RMM, Gomes AP, Maia TM, Magalhães KA, Marques ES, Siqueira-Batista R. Pobreza, injustiça e desigualdade social: repensando a formação de profissionais de saúde. Rev Bras Educ Med 2007; 31:278-86.
13. Secretaria de Assistência à Saúde, Ministério da Saúde. Portaria no ${ }^{\circ}$ 48, de 11 de fevereiro de 1999. Estabelece normas e procedimentos para Planejamento Familiar. Diário Oficial da União 1999; 17 fev.

14. Durães-Pereira MBBB, Novo NF, Armond JE. A escuta e o diálogo na assistência ao pré-natal, na periferia da zona Sul, no Município de São Paulo. Ciênc Saúde Coletiva 2007; 12:465-76

15. Gerhardt TE. Itinerários terapêuticos em situações de pobreza: diversidade e pluralidade. Cad Saúde Pública 2006; 22:2449-63.

16. Araújo MAL, Vieira NFC, Silva RM. Implementação do diagnóstico da infecção pelo HIV para gestantes em unidade básica de saúde da família em Fortaleza, Ceará. Ciênc Saúde Coletiva 2008; 13:1899-906.

17. Valla VV, Stotz EN, Guimarães MBL. Vigilância civil da saúde na atenção básica: uma proposta de ouvidoria coletiva na AP 3.1. Relatório da pesquisa. Rio de Janeiro: Escola Nacional de Saúde Pública Sergio Arouca, Fundação Oswaldo Cruz; 2005.

18. Núcleo Técnico da Política Nacional de Humanização, Ministério da Saúde. HumanizaSUS: acolhimento com avaliação e classificação de risco: um paradigma ético-estético no fazer em saúde. Brasília: Ministério da Saúde; 2004. (Série B. Textos Básicos de Saúde).

19. Núcleo Técnico da Política Nacional de Humanização, Ministério da Saúde. HumanizaSUS: documento base para gestores e trabalhadores do SUS 4a Ed. Brasília: Ministério da Saúde; 2008. (Série B. Textos Básicos de Saúde).

Recebido em 04/Nov/2009

Versão final reapresentada em 02/Jun/2010

Aprovado em 05/Ago/2010 